
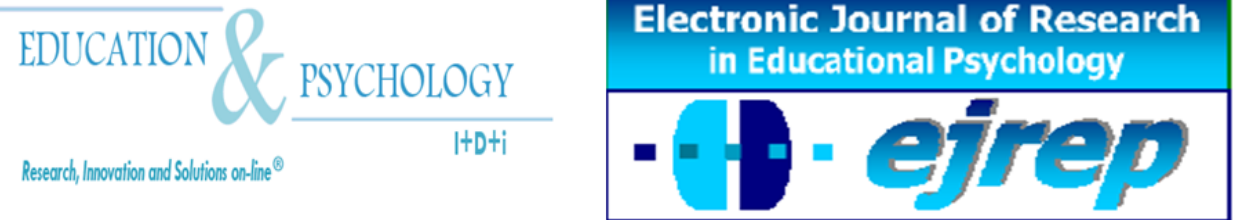

Editorial EOS

\title{
Modelo Teórico del Trastorno por Déficit de Atención con Hiperactividad I: Definición Operativa
}

Rocío Lavigne Cerván y Juan Francisco Romero Pérez

Departamento de Psicología Evolutiva y de la Educación, Universidad de Málaga

\section{España}

Correspondencia: Rocío Lavigne Cerván. Departamento de Psicología Evolutiva y de la Educación. Facultad de Psicología. Universidad de Málaga. Cámpus de Teatinos s/n. 29071. Málaga. España. E-mail: rlc@uma.es

(C) Education \& Psychology I+D+i and Editorial EOS (Spain) 


\section{Resumen}

Desde que en 1902 Still describiese las características de un Síndrome posteriormente denominado Trastorno por Déficit de Atención con Hiperactividad (TDAH, en lo sucesivo) han pasado más de cien años en los cuales se ha avanzado notablemente en cuanto a la conceptualización, búsqueda de su naturaleza, implicaciones y formas de evaluar y tratar el trastorno. De una visión completamente clínica, se pasó durante los años 60 a explicaciones psicoeducativas. Pero no fue hasta la década de los 80 cuando confluyen las dos líneas -médica y psicoeducativa-, gracias a las mejoras en las técnicas de neuroimagen y al auge de la neuropsicología. Esta visión, en cuanto al concepto y formas de abordar el tratamiento, continúa hoy día vigente en la comunidad científica y profesional y constituye la base en la que se sustenta el Modelo explicativo que sobre la definición operativa del TDAH se propone.

Palabras Clave: Trastorno por Déficit de Atención con Hiperactividad, Sistema Ejecutivo, Funciones Ejecutivas, Definición Operativa.

Recibido: 10/05/10 Aceptación Inicial: 11/05/10 Aceptación Definitiva: 08/07/10 


\title{
Theoretical Model of Attention Deficit with Hyperactivity Disorder I: Operational Definition
}

\begin{abstract}
Since 1902 when Still described the characteristics of a syndrome previously known as Attention Deficit Hyperactivity Disorder (ADHD), a hundred years have passed in which important advances have occurred, especially in conceptualization, the search for its nature, implications and ways of evaluating and treating the disorder. From a totally clinical point of view it progressed during the 60's to a psycho-educational approach. But it was not until the 80 's that the two methods met - medical and psycho-educational - thanks to the technical improvements in neuro-imagery and the development of neuropsychology. This point of view, specifically the concept and the ways of treating the disorder, continue to be applicable to the present day scientific and professional communities and constitutes the foundations that support the explicative model suggested for the operative definition of ADHD.
\end{abstract}

Keywords: Attention Deficit Hyperactivity Disorder, Executive System, Executive Functions, Operative Definition.

Received: 05/10/10 Initial Acceptance: 05/11/10 Definitive Acceptance: 07/08/10 


\section{Introducción}

El interés por el estudio del TDAH ha pasado por diferentes épocas en las cuales ha estado en la superficie de los centros de atención preferente de investigadores, profesionales y familiares, o bien ha permanecido oculto, pero no inexistente. En la actualidad, muy probablemente merced a los avances de la neurología, por un lado, y, por otro, a los cambios sociales y educativos que se han producido, el interés por el TDAH ha sobrepasado ampliamente los límites de los ámbitos de la investigación y el estudio académico, para constituirse en un fenómeno social, por el cual todo niño que muestre cierta actividad, que no permanezca sentado y quieto horas y horas en el colegio y en casa, o que no atienda de modo automático a todo lo que se le dice, es derivado a los especialistas bajo la sospecha de un posible TDAH.

Una parte de la responsabilidad de los elevados índices de sobrediagnóstico del TDAH (con porcentajes que en nuestro país a veces se dice que superan el 9\% de la población escolar entre 5 y 15 años de edad) radica en la falta de consenso acerca de qué es el TDAH y/o qué variables neuropsicológicas se encuentran implicadas en él, cuál es su origen, y, como consecuencia de todo ello, de criterios de diagnóstico unificados y de instrumentos de evaluación adecuados. Con respecto al tipo de instrumentos hay que precisar que a pesar de que existe una considerable gama en el mercado, no disponemos aún de un conjunto de tareas que nos ofrezcan una fiabilidad elevada respecto a lo que estamos evaluando (Lawrence et al., 2002; Root y Resnick, 2003). Además, pese a los esfuerzos dedicados a operacionalizar y medir las variables neuropsicológicas implicadas en el TDAH, como los procesos y funciones del sistema ejecutivo, todavía existen controversias en torno a qué son dichos procesos y funciones y qué test son los más adecuados para su evaluación (Félix, 2005, 2006; Miranda, Félix y Ávila, 2005). En un intento de dilucidar estas cuestiones, hemos elaborado una propuesta de Modelo explicativo y una definición operativa del trastorno y de los procesos psicológicos y comportamientos que lo caracterizan, a partir de la cual poder enfocar la evaluación, el diagnóstico y el tratamiento, proponiendo para ello un protocolo de actuación útil para poderlo abordar adecuadamente - esto último se desarrollado en un artículo diferente que será publicado en otro número de este Journal. 


\section{Antecedentes de la Definición Operativa del TDAH}

En la evolución del estudio del TDAH se aprecian dos líneas de investigación y de tratamiento diferenciadas, a veces divergentes y a veces, como ocurre actualmente, muy relacionadas. Una primera línea, se ha caracterizado por una consideración clínico-médica del trastorno (Hoffman, 1865, citado en Barkley, 2006a), George Frederich Still (1902 citado en Barkley, 2006a; Taylor, 1990), Hohman (1922) y Goldstein (1942), entre otros), que sería consecuencia de una gran variedad de posibles afectaciones: daño cerebral adquirido, disfunción cerebral mínima, alteración genética, incluso deficiencias en vitaminas y minerales, o dietas alimenticias excesivamente ricas en colorantes y conservantes, etc.; con propuestas de tratamientos también muy diversas, pero con el denominador común de ser el paciente del trastorno el objetivo preferente, sino único, de la intervención que se efectuaba mediante la prescripción de medicamentos cuyo fin primordial era disminuir la actividad motriz. Esta visión de la hiperactividad, aunque con sustantivos cambios en sus perspectivas conceptuales y terapéuticas, reapareció con fuerza a finales de los años 80 del siglo XX, gracias a importantes avances en neurología y neuropsicología y a la mejora de las técnicas de neuroimagen.

Una segunda línea, que se desarrolla con fuerza desde mediados del S. XX, es la denominada como psicoeducativa, que ha centrado su punto de mira en la conducta de las personas con TDAH, sobre todo en el ámbito escolar, dado que en ese tiempo era ésta, la conducta manifiesta, la única con posibilidades reales de ser abordada con ciertas garantías de éxito. Los científicos, Strauss y Werner (1942), Strauss y Laura Lehtinen (1947), Clements y Peters (1962), entre otros muchos, consideraron que el exceso de actividad motriz -hiperactividadera la característica principal del trastorno. Consideración que se modificó a partir de la década de los 70, pasando a ser la inatención -déficit de atención- el síntoma determinante, con lo que ya no sería la excesiva actividad la que provocase la debilidad en la atención, sino al revés. No obstante, los programas de tratamiento, además de intentar que la persona estuviera atenta y quieta, empezaron a ocuparse también de la familia y la escuela, proponiéndo pautas educativas, dando a entender con ello que el trastorno tenía una complejidad mayor de la que se le suponía.

Ambas líneas confluyen a finales de los años 80 en la aceptación común de que el TDAH es un trastorno de origen neuropsicológico que afecta a procesos psicológicos básicos para la adaptación social y afectiva, y para el aprendizaje (entre los cuales, además de la ina- 
tención y la falta de control inhibitorio de la conducta, se incluyen las dificultades en la autorregulación de las funciones ejecutiva). Por ello se propone que el trastorno debe ser abordado desde una perspectiva multidisciplinar que combine los avances neuro-farmacológicos con los psicoeducativos. Cada vez son más los investigadores y profesionales orientadores, terapeutas, etc. que sustentan esta visión interactiva, de entre ellos cabe mencionar a Barkley (1997a, 2006a, 2006b, 2008); Hinshaw y colaboradores, (1984); Miranda y colaboradores, (2002) y Romero y Lavigne (2005), entre otros muchos.

Desde principios de los años 90 del S. XX, las características mayoritariamente asumidas para describir el Trastorno por Déficit de Atención con o sin Hiperactividad, se encuentran incluidas en la cuarta edición del DSM (DSM-IV; APA, 1994); en su edición revisada (DSM-IV-TR; APA, 2001); y en la décima versión de la Clasificación Internacional de enfermedades -CIE, en lo sucesivo- (CIE-10); Organización Mundial de la Salud (OMS, 1995).

En la CIE-10, el TDAH, denominado Trastorno de la Actividad y la Atención se enmarca dentro de la sección de "Trastornos del comportamiento y de las emociones de comienzo habitual en la infancia y en la adolescencia”, en el subgrupo de Trastornos Hipercinéticos, en los que se delimitan tres categorías diagnósticas más: "Trastorno Hipercinético Disocial”; “Otros trastornos Hipercinéticos” y “Trastorno Hipercinético sin especificación”.

El DSM-IV (-TR), por su parte, sitúa el TDAH en el apartado de trastornos de inicio en la infancia, la niñez o la adolescencia, y más concretamente en el grupo de Trastornos por Déficit de Atención y Comportamiento Perturbador, junto con el "Trastorno Disocial", el "Trastorno Negativista Desafiante" y el "Trastorno de Comportamiento Perturbador no Especificado". De acuerdo con el planteamiento del DSM-IV (-TR), las dificultades de atención y/o hiperactividad e impulsividad, pueden dar lugar a un diagnóstico positivo con la delimitación de cuatro subtipos de TDAH: "Subtipo combinado"; "Subtipo con predominio del déficit de atención"; "Subtipo con predominio hiperactivo-impulsivo" y "Subtipo no especificado".

En resumen, la caracterización del TDAH según los dos esquemas diagnósticos principales, el DSM-IV (-TR) y la CIE-10, es casi idéntica. Por un lado, ambas clasificaciones coinciden en la exigencia del mantenimiento de las conductas a través del tiempo y de distintas situaciones con desajustes clínicamente significativos en, al menos, dos contextos distintos, tales como la escuela, el hogar, el trabajo o el grupo de compañeros, es decir, que con- 
ceptúan los problemas como rasgos del niño individual, y no como meras reacciones ante las situaciones. Por otro lado, sitúan como "piezas" clave en la descripción del trastorno, la presencia de síntomas de inatención, hiperactividad e impulsividad, aunque con unas sutiles diferencias entre un manual y otro ${ }^{1}$.

\section{¿Qué es el TDAH?}

Propuesta de una definición Operativa del TDAH

Partiendo del Modelo Híbrido de Barkley (1997a), de la conveniencia de que la consideración del trastorno debe hacerse desde una perspectiva psicoeducativa (familiar y escolar) -analizándolo desde de los procesos de enseñanza y aprendizaje reglados, en el marco de la escuela- y de la relación que guarda el TDAH con las Dificultades en el Aprendizaje ${ }^{2}$, se propone la siguiente definición operativa (véase figura 1):

"El TDAH es un término específico que se refiere a un grupo de trastornos escolares y no escolares, que se manifiestan como dificultades significativas para el aprendizaje y la adaptación familiar, escolar y social. El TDAH puede darse a lo largo de toda la vida de la persona, pero se manifiesta de forma particularmente álgida en el periodo vital comprendido entre el nacimiento y la adolescencia. Este trastorno es intrínseco a la persona que lo padece, es decir, es debido a un retraso en el desarrollo neuropsicológico que provoca disfunciones en los mecanismos de Control Ejecutivo e Inhibición del Comportamiento, que afecta de modo directo a los Procesos Psicológicos del Sistema Ejecutivo -tales como la memoria de trabajo y su relación con el sistema de atención anterior, la autorregulación de la motivación y el afecto, la interiorización del lenguaje y los procesos de análisis y síntesis-y a sus Funciones Ejecutivas -como la planificación y organización, la automonitorización y evaluación, la

\footnotetext{
1 Mientras, el DSM IV (-TR) requiere como mínimo seis síntomas de inatención o de hiperactividadimpulsividad, la CIE-10, requiere al menos seis de inatención, tres de hiperactividad y uno de impulsividad. Por lo que en esta última, deben de estar presentes los tres síntomas, sin embargo en el DSM con uno de los síntomas se puede proceder al diagnóstico, siempre que se cumplan los demás requisitos comentados anteriormente.

${ }^{2} \mathrm{Si}$ imaginamos un continuum representado por factores patológicos personales, factores definidos por la interacción persona-ambiente y factores ambientales, en el cual en un lado se sitúen las condiciones personales y en el otro las ambientales, podemos diferenciar a los alumnos con DA según las posiciones que ocupen en dicho continuum, a tenor de la valoración que cada uno de ellos merezca en función de tres criterios: gravedad, afectación y cronicidad. De acuerdo con ello, se distinguen cinco tipos o grupos de DA que irían de menor a mayor grado de gravedad, afectación y cronicidad: siendo los problemas escolares las de tipo I; el bajo rendimiento escolar las de tipo II; las dificultades específicas en el aprendizaje las de tipo III; el TDAH las de tipo IV; y la discapacidad intelectual límite las de tipo V, (Romero y Lavigne, 2005).
} 


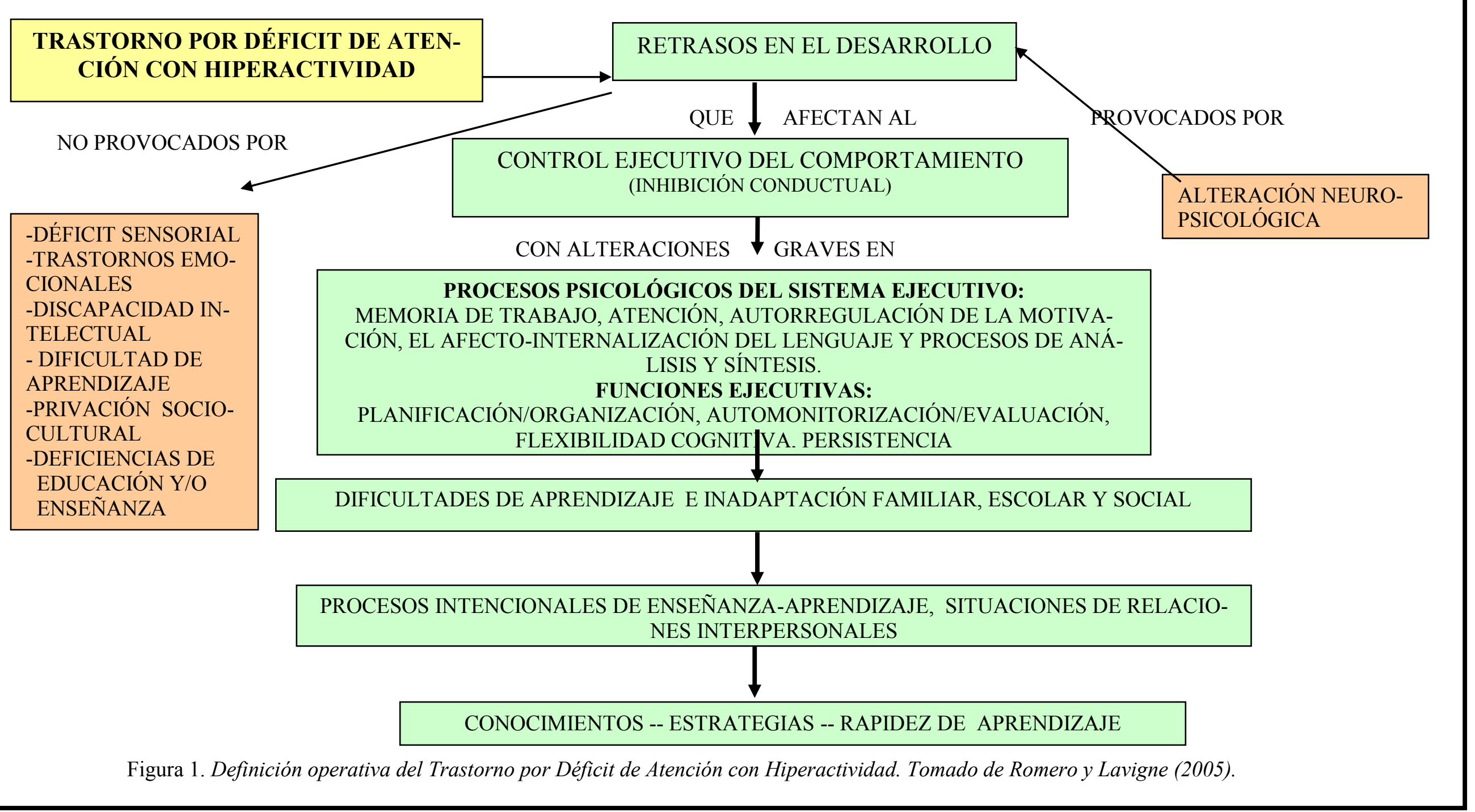


flexibilidad cognitiva y la persistencia-, implicadas directamente en las tareas de enseñanzaaprendizaje y en la adaptación escolar, social y familiar. Aunque el TDAH puede ocurrir conjuntamente con otros trastornos (por ejemplo: deficiencia sensorial, discapacidad intelectual, trastornos emocionales graves, dificultades especificas de aprendizaje) o con influencias extrínsecas (por ejemplo: diferencias culturales, deficiencias o inadecuaciones educativas, instrucción inapropiada o insuficiente), no es el resultado de estas condiciones o influencias."

Como es apreciable en su definición operativa, en el TDAH intervienen un considerable número de procesos neuropsicológicos estrechamente imbricados entre sí, que a su vez inciden sobre otros procesos, en una red sistémica que afecta al desarrollo y la adaptación familiar, escolar y social de las personas que lo padecen. A continuación se destacarán de forma más detallada los principales procesos neurológicos y psicológicos que constituyen el núcleo central del TDAH.

Procesos Neurológicos y Psicológicos implicados en la Definición Operativa del TDAH:

\section{El Sistema Ejecutivo}

El Sistema Ejecutivo se activa cuando una acción, no rutinaria, está encaminada a la consecución de un objetivo, hay una dilación temporal entre los elementos de la secuencia de la conducta (evento/respuesta/consecuencia), existe un conflicto entre las consecuencias inmediatas y a largo plazo de la respuesta, y los requerimientos de la acción suponen una respuesta compleja por parte del sujeto que necesita organizarse en el tiempo (Barkley, 1997a, 1997b, 2002). Por lo tanto, no intervendrá en todas las situaciones que se le presenten al sujeto, sino sólo en aquellas en las que deba realizar un acción finalista, que exija inhibir las respuestas habituales, que requieran planificación y toma de decisiones y que precisen del ejercicio de procesos psicológicos como la memoria de trabajo, el sistema de atención anterior, los procesos de análisis y síntesis y la autorregulación de la motivación y el afecto. Se trata, por tanto, de un Sistema consciente que ejerce control sobre las conductas complejas, novedosas, dirigidas a un fin y voluntariamente determinadas, que exigen atención específica por parte del sujeto. Algunos autores lo definen como el Sistema responsable de controlar los procesos necesarios para resolver problemas y conseguir objetivos futuros (Pennington, 1991; Pennington y Ozonoff, 1996). Otros señalan que el Sistema Ejecutivo es crucial para organizar e inte- 
grar los procesos cognitivos a lo largo del tiempo y que desempeña un papel cada vez más importante a medida que los niños maduran, llevan a cabo tareas más complejas y participan en actividades más independientes, menos regladas y reguladas (Denckla, 1996a, 1996b). Además, añaden que el crecimiento consiste esencialmente en el desarrollo de la capacidad de las funciones del mencionado Sistema, debido a que gran parte del soporte neuroanatómico y funcional del mismo reside en los lóbulos frontales y sus conexiones, y a que en estas áreas la mielinización no se completa hasta la tercera década de la vida (Herschkowitz, 1988). Por lo que nos encontramos ante un Sistema cuyas funciones cerebrales son de las más evolucionadas y de las últimas en desarrollarse por completo.

\section{Componentes Estructurales del Sistema Ejecutivo:}

Al hablar de los componentes estructurales del Sistema Ejecutivo (véase figura 2) se hace referencia a aquellos componentes del Sistema Nervioso Central, que se encuentran implicados en el TDAH (Barkley, 1997a, 2006a; Casey et al. 1997; Castellanos et al. 1996, 2002, 2004; Faraone y Biederman, 1998; Willcutt et al. 2005, entre otros) como los lóbulos frontales y su relación con el cerebelo y con algunas estructuras subcorticales, como los ganglios basales.

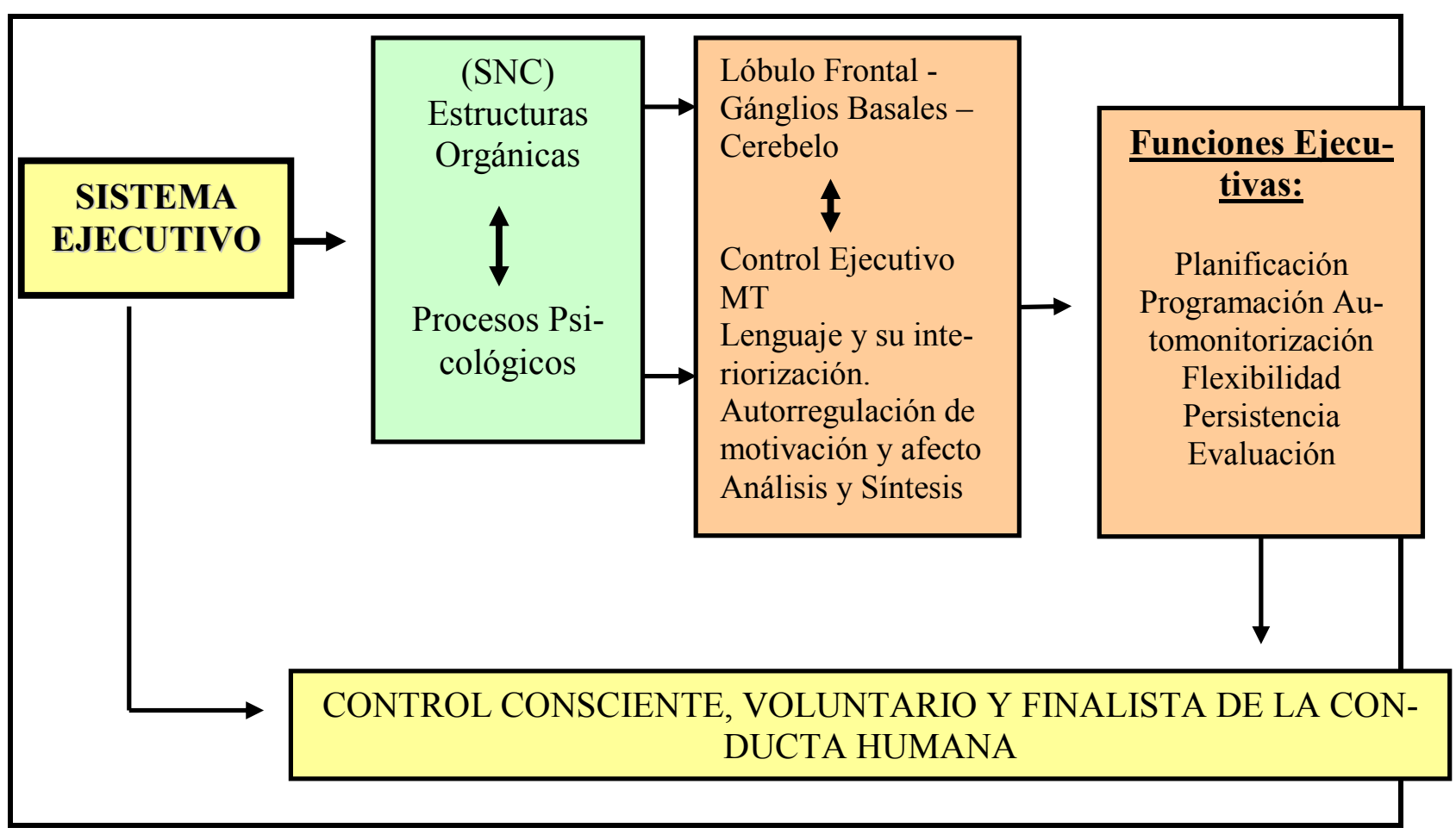

a. SNC: Sistema Nervioso Central. b. MT: Memoria de Trabajo.

Figura 2. Componentes del Sistema Ejecutivo. 


\section{1.- Los Lóbulos Frontales:}

Constituyen la porción anterior de cada hemisferio cerebral. Estas estructuras suelen dividirse en la corteza frontal y la prefrontal, para diferenciar las zonas posteriores y anteriores respectivamente. La región prefrontal, que a su vez se subdivide en diferentes áreas (dorsolateral, orbital y medial), parece ser la más directamente relacionada con el Sistema Ejecutivo (Fuster, 1997; Wheeler et al., 1997).

Los lóbulos frontales no tienen asignadas una única función, sino que "tienen a su cargo" fascinantes funciones muy diversas y muy importantes para el ser humano. Durante las últimas décadas, el estudio de las funciones de los lóbulos frontales ha sido el objetivo de una intensa investigación científica, que aún está en curso y, a falta de conceptos más precisos (Goldberg, 2004). No obstante, de lo que no cabe duda es que la corteza prefrontal desempeña el papel central de inhibir la conducta, mantener la atención, usar el autocontrol, establecer fines y objetivos y posteriormente concebir los planes de acción necesarios para alcanzarlos utilizando para ello el lenguaje (reglas o instrucciones). Con el objetivo de poder llevar a cabo todas estas tareas, selecciona las habilidades cognitivas necesarias, las coordina y aplica en orden correcto y finalmente, evalúa el éxito o fracaso de las mismas en función de los fines que se pretendían conseguir. Las personas con TDAH encuentran muchas dificultades para ejecutar de forma correcta todas y cada una de las tareas mencionadas.

Los lóbulos frontales, también son el mecanismo por el cual el organismo se libera a sí mismo del pasado y se proyecta hacia el futuro. Es decir, permite crear modelos -mentales- de situaciones, como prerrequisitos para hacer que las cosas sucedan, modelos de algo que todavía no existe pero que uno quiere traer a la existencia. Para evocar una representación interna del futuro, el cerebro debe tener la capacidad de tomar ciertos elementos de experiencias previas y reconfigurarlos de tal forma que en su totalidad no corresponda a ninguna experiencia pasada real. Para conseguirlo, el organismo debe adquirir la capacidad de manipular y transformar las representaciones internas. Esta capacidad, que se encuentra dañada en los sujetos con TDAH, depende críticamente de la corteza prefrontal, y la emergencia de la misma va en paralelo con la evolución y el desarrollo de los lóbulos frontales y, por tanto, de sus funciones ejecutivas. 
La corteza prefrontal es probablemente la parte mejor conectada del cerebro (Barkley, 1997a, 2006a, 2008; Brown, 2003; Goldberg, 2004). Esta conectividad hace a los lóbulos frontales singularmente apropiados para coordinar e integrar el trabajo de todas las demás estructuras cerebrales. Parafraseando al neuropsicólogo Elkhonon Goldberg (2004, p. 52), "los lóbulos frontales ejercen un papel similar al del director de una orquesta". De tal forma que si "el director no cumple su función el resultado de la obra no será el esperado".

En relación con el TDAH, éste se presenta como un trastorno cuyo origen presumiblemente se debe a una disfunción del área frontal cerebral (Barkley, 1997a, 2006a, 2006b; Castellanos, 2002, 2004; Casey et al., 1997; Faraone y Biederman, 1998, entre otros), “del director de la orquesta". Por lo que, una alteración en el desarrollo de dichas áreas afectará al funcionamiento de otras con las cuales se encuentren interconectadas (ganglios basales, cerebelo, etc.). Áreas que ayudan a desarrollar funciones que las personas con TDAH muestran serias dificultades en desempeñar de forma adecuada.

Estas zonas cerebrales son las más ricas en dopamina. Algunas de las hipótesis explicativas del TDAH indican que posiblemente la dopamina no actúe eficazmente (Barkley, 2006a, 2006b; Díaz-Heijtz et al., 2006; Mulas et al., 2007; Teicher et al., 2000; entre otros), mostrándose una menor actividad cerebral (Barkley, 2006a, 2006b; Capilla-González et al. 2005; Ernst et al., 1997, entre otros) que repercutirá sobre la inhibición de la conducta, la demora en la respuesta a la situación y el mantenimiento de la atención durante periodos largos de tiempo.

En resumen, los hallazgos de diferentes estudios han puesto de manifiesto que el déficit cognitivo central del trastorno reside en una disfunción ejecutiva relacionada con varias regiones específicas del cerebro. Todo ello, debido fundamentalmente a una menor actividad eléctrica y menor reactividad a los estímulos en estas regiones, que se traduce en una alteración en la neurotransmisión de la dopamina y noradrenalina y como consecuencia en la desregulación de la corteza frontal y los circuitos subcorticales modulados por estos neurotransmisores (Barkley, 2002; Castellanos y Tannock, 2002).

Además de los lóbulos frontales, existen otras estructuras cerebrales interconectadas con ellos que son importantes para la comprensión del TDAH. A continuación, se analiza el papel que juegan en el TDAH los ganglios basales, por un lado, y el cerebelo, por otro. 


\section{2.- Ganglios Basales:}

Son un conjunto de estructuras localizadas profundamente en la base del encéfalo, formada por unos núcleos interconectados a través de un circuito cerebral, el tálamo y el tallo cerebral. El grupo más grande de estos núcleos es el cuerpo estriado -región importante para la inhibición de la conducta y el mantenimiento de la atención- formado por el núcleo caudado, el putamen, el globo pálido y el núcleo accumbens.

El núcleo caudado, es una estructura importante en las vías que unen la zona frontal con las estructuras del cerebro medio, conocidas como el sistema límbico. Este sistema es el responsable de una gran variedad de actividades humanas, entre las que se encuentran el control de las emociones, la motivación y la memoria. A través de estas vías y conexiones, el sistema límbico envía señales hacia la zona frontal del cerebro, la cual a su vez, envía sus propias señales hacia el sistema límbico como un medio de control y regulación de la conducta y las emociones.

En general, los ganglios basales se encuentran asociados a varias funciones como el control motor, emocional y funciones del Sistema Ejecutivo. Concretamente, contribuyen a desconectar las respuestas automáticas posibilitando que el cortex prefrontal delibere con más detenimiento, y que se coordinen entre las diversas regiones del cortex, las informaciones neurológicas (Mulas y Morant, 2006).

Las personas con TDAH muestran una disfunción en los circuitos frontoestriatales que unen las zonas frontales del cerebro con los ganglios basales-, debida fundamentalmente a un déficit en varios neurotransmisores, en especial la dopamina (Frazer et al., 1999). Todo ello se traduce en una hipoactivación de los lóbulos frontales (concretamente de la corteza prefrontal del hemisferio derecho), del núcleo caudado y de la corteza cingulada anterior (Bush et al. 1999; Teicher et al., 2000). Esta última región, se considera esencial para el correcto funcionamiento de los circuitos y se ha relacionado con una amplia gama de funciones del Sistema Ejecutivo como la autorregulación de la motivación y el afecto. Funciones, que los sujetos con TDAH muestran serias dificultades en desempeñar.

\section{3.- Cerebelo:}


Es una región del encéfalo cuya función principal es la de integrar las vías sensitivas y las vías motoras. Existe una gran cantidad de haces nerviosos que conectan el cerebelo con otras estructuras encefálicas y con la médula espinal. El cerebelo integra toda la información recibida para precisar y controlar las órdenes que la corteza cerebral manda al aparato locomotor a través de las vías motoras. Sin embargo, las investigaciones más actuales han mostrado que el cerebelo tiene un papel más amplio, ya que se encuentra relacionado con procesos cognitivos. Concretamente, se comporta como un centro de procesamiento de información que llega a través de conexiones bidireccionales desde regiones encargadas de la atención, la percepción visoespacial, la memoria y de la regulación de funciones ejecutivas y emocionales (Hernández-Muela et al., 2005). Esta extensa conexión entre córtex y cerebelo, sobretodo en regiones prefrontales dorsolaterales, avala su papel en relación con el mantenimiento de la memoria de trabajo, la resolución de problemas y las funciones ejecutivas.

A través de la neuroimagen, diversas investigaciones han podido demostrar que en las personas con TDAH existen diferencias estructurales en esta y otras áreas mencionadas si las comparamos con sujetos que no padecen el trastorno (Berquin et al., 1998; Castellanos et al., 2002, 2004; Martín et al., 2010, entre otros). Concretamente, a través de diferentes estudios de neuroimagen estructural, se han encontrado hallazgos en las personas con TDAH como los siguientes: Los lóbulos frontales parecen ser más pequeños, sobre todo el lóbulo frontal derecho (Castellanos et al. 1996; Castellanos et al., 2002; Castellano y Acosta, 2004; Filipek et $a l .$, 1997); Muestran un menor volumen cerebral en distintas zonas de los ganglios basales (el cuerpo estriado es el que se encuentra más afectado). Además, la asimetría del núcleo caudado derecho es mayor que la del izquierdo. No obstante, algunas investigaciones consideran que la asimetría de los núcleos basales es normal (hemisferio izquierdo mayor que el derecho) (Castellanos et al. 1996; Filipek et al. 1997); El volumen de los hemisferios cerebelosos también parece ser más pequeño (Castellanos et al. 1996; Castellanos et al., 2002; Castellano y Acosta, 2004). Concretamente, los lóbulos postero-inferiores del vermis cerebeloso son más pequeños, pero con conservación del lóbulo promedio del resto del órgano.

Desde un punto de vista funcional, los estudios realizados con tomografía por emisión de positrones ("PET"), muestran una disminución en el metabolismo cerebral de la glucosa en el lóbulo frontal (Zametkin et al., 1990; Zametkin et al. 1993). Otros estudios con tomografía por emisión de fotón único (“SPECT"), han encontrado la existencia de una relación inversa entre el flujo sanguíneo cerebral en regiones frontales del hemisferio derecho y la gravedad de 
los síntomas conductuales (Gustafsson et al., 2000). Así mismo, estudios realizados mediante resonancia magnética funcional (RMf) han puesto de manifiesto que en comparación con sujetos sin TDAH, las personas con el trastorno presentan una menor actividad en la corteza prefrontal del hemisferio derecho (Rubia, Overmeyer y Taylor, 1999; Teicher, Anderson y Polcari, 2000), en los ganglios basales, concretamente en el núcleo caudado (Teicher et al., 2000), y en el cerebelo (Pine, 2001). En otras investigaciones también han encontrado una hipoactivación en la corteza cingulada anterior (Bush et al., 1999; Bush, 2008), -región que se considera esencial para el correcto funcionamiento de los circuitos fronto-estriatales y que se ha relacionado con una amplia gama de funciones ejecutivas-. En definitiva, según estas explicaciones las personas con TDAH presentan menor actividad cerebral y menor reactividad a los estímulos (Capilla-González et al., 2005; Barkley, 2006a; Ernst, Zametkin, Phiplips y Cohen, 1997) -tal y como se ha mencionado anteriormente-. Las diferencias que en este aspecto muestran en comparación a personas sin ningún tipo de trastorno, han sido corroboradas a través de diferentes investigaciones, pero cuál, o cuáles, sea la causa última sigue siendo objeto de investigación, porque las diferencias halladas en morfología y su relación con la sintomatología presente en el TDAH, no son suficientemente significativas como para explicar por sí solas lo que ocurre en el trastorno.

Por lo tanto, el TDAH se presentaría como un trastorno debido presumiblemente a una alteración en el desarrollo neuropsicológico ${ }^{3}$ que provoca una disfunción frontoestriada, e incluye a regiones cerebrales prefrontales, a núcleos de la base y a regiones del cerebelo, y que afectaría al óptimo desarrollo de las funciones del Sistema Ejecutivo (Barkley, 1997a, 2006a, 2006b; Bradley y Golden, 2001; Frazer et al., 1999).

\section{Componentes Psicológicos del Sistema Ejecutivo:}

Los componentes psicológicos implicados en el Sistema Ejecutivo son: el control ejecutivo del comportamiento, la memoria de trabajo, la atención, el lenguaje y su interiorización, la autorregulación de la motivación y el afecto, y los procesos de análisis y síntesis.

\footnotetext{
${ }^{3}$ Originada, según algunas de las hipótesis que en los últimos años están cobrando más relevancia, por una alteración en los genes (Faraone, 2004; Faraone et al., 2005; Barkley 2006a, 2006b, 2008; entre otros) que regulan la información acerca de la recepción y/o el transporte de neurotransmisores como la dopamina y noradrenalina muy presentes en las estructuras cerebrales explicadas.
} 


\section{1.- Control Ejecutivo del Comportamiento:}

El Control Ejecutivo hace referencia a la capacidad que posee una persona de inhibir su conducta, es decir, de controlar su comportamiento -motor y lingüístico-, para autorregular su pensamiento, limitar la influencia de estímulos externos y responder - o no- a los acontecimientos en función de lo que se demande en cada momento.

La falta de inhibición de la conducta es el factor primario en el TDAH, del cual derivan el resto de sus dificultades de aprendizaje, y de adaptación social, escolar y familiar. Como resultado de esta falta de inhibición conductual, los sujetos con TDAH presentan -en cualquier escenario- una actividad motriz incesante, inadecuada e inoportuna, que resulta extremadamente inadaptativa y que limita seriamente las posibilidades de aprendizaje escolar y las relaciones interpersonales.

Una segunda consecuencia del problema con la inhibición -también presente en cualquier escenario y situación- es que las personas con TDAH muestran una significativa dificultad en el control del Sistema de Atención Anterior, imprescindible para el control ejecutivo, coordinado y reflexivo del pensamiento y la conducta.

De modo que de la falta de inhibición conductual -como factor primario- se derivan dos factores secundarios: hiperactividad y déficit de atención. De los cuales, a su vez, proceden otros factores como: impulsividad, déficit en memoria de trabajo, déficit en autorregulación de la motivación y el afecto, déficit en la interiorización de lenguaje y en los procesos de análisis y síntesis (Barkley 1997a, 2006a, 2008).

La capacidad para inhibir la conducta, empieza a desarrollarse hacia el final del primer año de vida, y continúa hasta la década de los veinte años. A medida que aumenta la madurez lo hace también la capacidad para demorar la conducta durante un mayor período de tiempo en función de las demandas de la actividad que se esté realizando. Las personas con TDAH, desarrollan de forma tardía estas habilidades, por lo que serán menos eficaces que otras de su misma edad al ponerlas en práctica. Todo ello debido a que no pueden inhibir su conducta durante el tiempo suficiente como para que los demás procesos psicológicos del Sistema Ejecutivo y sus Funcione Ejecutivas puedan tener lugar adecuadamente. Por fortuna, el trata- 
miento farmacológico ${ }^{4}$ ejerce un importante papel para muchas personas con TDAH ya que permite mejorar temporalmente su habilidad para inhibir la conducta y esperar antes de responder. Esto parece tener efectos colaterales positivos sobre los otros procesos psicológicos relacionados. De esta forma, las personas con TDAH medicadas procesarán la información de una manera más parecida a las de su misma edad y sin el trastorno, por lo que serán capaces de mostrar un mayor autocontrol, de dirigir eficazmente su conducta hacia el futuro y de liberarse de estar controladas por los acontecimientos del momento.

\section{2.-La Memoria de Trabajo:}

La importancia del papel desempeñado por la memoria de trabajo (MT, en lo sucesivo) en el TDAH viene siendo puesta de manifiesto desde la segunda mitad de la década de los ochenta del siglo pasado. Importantes estudios indican que las diferencias entre personas con TDAH y sin TDAH en las tareas escolares son debidas a limitaciones de la MT que afectan más al modo en que es usada que a su capacidad (Swanson, 2000; Wilson y Swanson, 2001, entre otros).

La MT se define como un mecanismo de procesamiento de la información de capacidad limitada, que se ocupa del mantenimiento activo de la representación de la información mientras, simultáneamente, dicha información, u otra, está siendo procesada. Se trata, por tanto, de uno de los componentes cognitivos más importantes de la capacidad ejecutiva, crucial para la realización de las operaciones y conductas que se insertan bajo el dominio de las funciones ejecutivas (Baddeley, 1986, 1990, 1992, 1996, 2000; Baddeley et al., 1994; Swanson, 1996).

Baddeley describe a la MT como un sistema de almacenamiento temporal y limitado que permite retener al mismo tiempo algunos datos de información en la mente, compararlos, contrastarlos o, en su lugar, relacionarlos entre sí. Además, se responsabiliza del almacenamiento a corto plazo a la vez que manipula la información necesaria para los procesos cognitivos de mayor complejidad como la comprensión del lenguaje hablado y escrito, la lectura, el razonamiento, etc. La MT se fragmenta en subcomponentes diferenciados: el bucle fonológico, la agenda visoespacial y el ejecutivo central. Tanto el bucle fonológico, como la agenda

\footnotetext{
${ }^{4}$ Mediante la administración de metilfenidato o atomoxetina (compuestos químicos de los fármacos comunmente utilizados para el tratamiento del TDAH).
} 
visoespacial, están en permanente contacto con el ejecutivo central (EC, en lo sucesivo), el cual, al tiempo que se ocupa de la coordinación de la actividad dentro del sistema cognitivo, también dedica una parte de sus recursos a incrementar la cantidad de información (fonológica y/o visoespacial) que puede ser almacenada en los dos subsistemas pasivos anteriores.

Para definir el concepto de EC y los procesos que intervienen en él Baddeley, opta por recurrir al concepto de sistema atencional supervisor (SAS, en lo sucesivo), de Norman y Shallice $(1980,1986)$. Según estos autores, el SAS se pone en funcionamiento ante tareas intelectuales complejas, -no rutinarias o novedosas, orientadas a un fin- y activa los procesos relacionados con la recuperación y el almacenamiento de la información en la MLP. Para ello, necesitará hacer uso del sistema de atención anterior (SAA, en lo sucesivo), imprescindible en el control ejecutivo, coordinado y reflexivo del pensamiento y la conducta, (Romero y Lavigne, 2005).

El SAA ${ }^{5}$, juega un papel importante en el procesamiento de la información interna (modelo top-down o de arriba-abajo) proveniente del sujeto. Se trata de un procesamiento reflexivo, orientado a una meta y dirigido por el SAS, en el que el SAA actúa como un instrumento. El SAA se subdivide en tres tipos de atención:

1) Atención Selectiva: hace referencia a la capacidad de centrarse en un estímulo, obviando los que no son relevantes y que distraen de la tarea en curso.

2) Atención Sostenida: es la que permite al sujeto mantener la atención focalizada en una misma tarea durante un período de tiempo prolongado.

3) Atención Dividida: consiste en la capacidad de atender a más de un estímulo o tarea relevante al mismo tiempo.

Las bases neuroanatómicas del SAA se asientan fundamentalmente en el córtex prefrontal y en sus múltiples conexiones con otras áreas subcorticales, como los ganglios basales (Cummings, 1993).

\footnotetext{
${ }^{5}$ El concepto de atención es complejo: al mencionado SAA, se añaden el Sistema de Alerta, de vigilia (arousal) o de atención tónica, básica; y el Sistema de Atención Posterior (llamado así por su localización en zonas posteriores del cerebro) que se ocupa de la atención sensorial general, es decir, de información proveniente del exterior. Ambos son necesarios -aunque no suficientes- para la correcta actuación del SAA.
} 
Se puede apreciar, que el núcleo fundamental para la actividad de la MT es el EC, si falla difícilmente la MT tendrá representaciones con las que operar y activar a la MLP. Las personas con TDAH, presentan menor eficacia en la codificación de los estímulos y una acusada tendencia a "prolongar" la activación el estímulo vigente. Por todo lo cual, se les cataloga de "olvidadizos" y de que "sólo viven el presente" sin prestar atención a las consecuencias futuras de sus actos, ni a la proyección hacia metas en el tiempo. Pero no se trata tanto de un problema estructural de la MT, como de una utilización menos adecuada de estrategias de codificación y de recuerdo. Por lo tanto, lo que varía con respecto a sujetos que no padecen TDAH es el "uso" que hacen de la MT, es decir, el modo en que operan con la información antes de emitir una respuesta en función de las demandas de la tarea, en el mencionado EC.

Como venimos poniendo de manifiesto, el TDAH entraña con frecuencia una concepción muy amplia que en ocasiones induce a errores en el diagnóstico: ¿Podemos encontrarnos con sujetos con TDAH sin hiperactividad?, ¿y sin déficit de atención?, ¿realmente las clasificaciones vigentes en el DSM-IV-TR o en la CIE-10 responden a la realidad?. Barkley (2006a, 2006b, 2008, 2009), señala que la subtipificación del trastorno es el resultado de tener dos listas de síntomas - como se puede apreciar en el DSM-IV-TR y en la CIE-10-, pero que no parecen responder a los subtipos reales (Barkley, 2006a). El subtipo con predominio de hiperactividad-impulsividad, constituye una fase previa a la aparición del subtipo combinado. Es decir, son niños más jóvenes -generalmente menores de 5-6 años- que en los próximos años serán diagnosticados como TDAH subtipo combinado. El subtipo con predominio de déficit de atención, hoy por hoy constituye un "contenedor" en el que se "arroja" todo. Barkley hace una distinción muy interesante entre tres subgrupos dentro del subtipo que nos ocupa, se trata de:

A) Individuos que inicialmente presentan el subtipo combinado, pero han crecido. Evolutivamente, la hiperactividad -entendida como un exceso de actividad motora- desciende. De tal manera que si utilizamos con adolescentes los criterios del DSM-IV-TR para volverlos a evaluar, probablemente el diagnóstico variaría al subtipo inatento, ya que no cumpliría con los seís síntomas de hiperactividad, lo cual se aparta de la realidad. Verdaderamente, lo único que nos indicaría es que el sujeto está creciendo y que los síntomas de hiperactividad han mermado, ya que el diagnóstico de TDAH subtipo combinado, en estos casos, no debe ser cambiado.

B) Niños que tienen prácticamente todos los síntomas del subtipo combinado -según el DSM-IV- excepto uno. En estos casos, estamos ante una forma leve del subtipo combinado. 
El TDAH subtipo combinado se considera -como otros trastornos- dentro de un continuum en el que hay formas leves, moderadas, graves y profundas del trastorno.

C) Un nuevo trastorno ${ }^{6}$ : individuos de "Tempo Cognitivamente Lento" (TCL, en lo sucesivo) - "Slow Cognitive Time”-. Comprenden el “30-50\%”, (Barkley, 2006a, p. 87, 2009), de los sujetos que hoy día hay diagnosticados como TDAH subtipo con predominio de atención en los Estados Unidos. Sus síntomas son opuestos a los de los TDAH subtipo combinado, son: hipoactivos; lentos en sus movimientos; letárgicos; calmosos; callados; apáticos; descuidados; despistados; y con tendencia a soñar despiertos. En las relaciones con sus iguales, los TDAH subtipo combinado, padecen un claro y activo rechazo de sus iguales porque son más agresivos, se pelean, no respetan turnos en el juego,..., sin embargo los TCL, sufren con más frecuencia aislamiento social, olvido o abandono por parte de sus compañeros. En cuanto a la comorbilidad, los TCL tienen mayor probabilidad de presentar dislexia, discalculia, ansiedad, depresión, mientras que los TDAH subtipo combinado, trastornos de conducta y trastorno oposicionista desafiante. Además, en relación al tratamiento, los TCL responden menos favorablemente a los psicoestimulantes. Concretamente, el $65 \%$ de los sujetos con TCL mejoran pero no lo suficiente, frente al 90\% de los sujetos con TDAH subtipo combinado que mejoran significativamente. Sin embargo, la terapia cognitiva resulta ser más eficaz en los sujetos con TCL, que en los niños con TDAH -en caso de abordar el problema desde una perspectiva unimodal-.

Como vemos, se propone un nuevo trastorno, que no sería TDAH, aunque sí presentan déficit de atención, pero el tipo de inatención que manifiestan refleja probablemente deficiencias en la rapidez de procesamiento de la información y en la atención selectiva o focalizada -es decir, en el input-, problemas cualitativamente diferentes a los que manifiestan los TDAH, que afectan especialmente a la persistencia y a la distractibilidad -en el output-. Además, el perfil neuropsicológico y social, la comorbilidad, la respuesta al tratamiento farmacológico y a la terapia psicológica,..., es sustancialmente diferente en un caso y en otro.

Todo ello significa que estamos ante trastornos diferentes, y que probablemente en el próximo DSM todos estos cambios se vean reflejados, y los TCL, sustituyan al actual TDAH subtipo inatento y aparezcan como un nuevo trastorno diferente del TDAH. De tal manera que el único TDAH que permanezca sea el subtipo combinado.

\footnotetext{
${ }^{6}$ No se trataría, por tanto, de TDAH.
} 


\section{3.-El Lenguaje y su interiorización:}

El lenguaje asume, a lo largo del desarrollo, una función esencial: la de ser instrumento del pensamiento y del control metacognitivo. Vygotski y Luria atribuyeron al lenguaje un papel central en la formación de los procesos cognoscitivos y teorizaron e investigaron en torno a su rol en la actividad voluntaria dirigida. El acto voluntario, que implica todas las funciones del Sistema Ejecutivo, fue conceptuado como el resultado de un proceso de transformaciones mentales en la ontogénesis que tiene su origen en la actividad social. Estas transformaciones comienzan con instrucciones verbales por parte de los adultos en el entorno del sujeto y terminan con la acción por parte de éste. Es sólo cuando el sujeto aprende a hablar y se apropia del lenguaje, el momento en el que comienza a regular su propia actividad a través del mismo. Por tanto, el lenguaje social se transforma en lenguaje interno y desde ahí, inicia y perfecciona su función autorreguladora.

En cuanto al lenguaje interno, que facilita la guía y el control de la conducta ("ahora debo hacer esto", "debo fijarme bien para no equivocarme”, etc.), Barkley (2002, 2006a, 2008) argumenta que las personas con TDAH tienen retraso en la interiorización del lenguaje y en su integración. El lenguaje interno es un fundamento importante del juego y de la conducta adaptativa. Esta inmadurez en la interiorización del lenguaje también puede ser la causa de las dificultades de las personas con TDAH para adoptar un comportamiento gobernado por reglas y del retraso en el desarrollo moral. De hecho, si se analiza el comportamiento del niño con TDAH se puede comprobar cómo no suelen ser "malos" en el sentido moral del término, sino que difícilmente pueden comportarse de otro modo.

En relación con las dificultades del lenguaje, propiamente dichas, algunos autores señalan que, en general, son uno de los problemas que con mayor frecuencia aparecen asociados al TDAH. Varios estudios clínicos y epidemiológicos de niños con trastornos psiquiátricos y con alteraciones del lenguaje han sugerido un vínculo específico entre TDAH y alteraciones del habla y del lenguaje (Miranda et al., 1998; Baker y Cantwell, 1992; Tannock y Schachar, 1996, entre otros). El déficit en las habilidades lingüísticas básicas (procesamiento fonológico, semántico y morfosintáctico) parece darse entre niños con TDAH y/o con dificultades específicas en el aprendizaje de la lectura. Sin embargo, son las dificultades pragmáticas las que resultan estar más afectadas en el TDAH puro sin comorbilidad, debido a que "la habilidad pragmática es una habilidad compleja, compendio de habilidades lingüísticas y cogniti- 
vas, que requiere una alta exigencia [del Sistema Ejecutivo y de sus funciones]" (Ygual, 2003, p.84).

\section{4.- La Autorregulación de la Motivación y el Afecto:}

Barkley (2002) señala que ser capaz de inhibir el impulso a responder, y esperar, proporciona al cerebro tiempo para separar la información que le llega en dos partes: el sentido personal -es decir, las emociones y/o sentimientos ${ }^{7}$ que se suscitan en el sujeto- y la información o el contenido del evento. Esta capacidad para retrasar la respuesta, ofrece la posibilidad de poder evaluar los acontecimientos de una manera más objetiva, racional y lógica. De tal forma que las reacciones iniciales que se susciten en el sujeto sean auto-reprimidas, automoderadas y auto-controladas para ser más aceptables socialmente, y más eficaces en la toma de decisiones. Por lo tanto, se debe aprender a auto-regular las emociones antes de mostrárselas a los demás, (o lo que es lo mismo, poder establecer una coordinación ejecutiva entre los lóbulos frontales -encargados de la lógica y el razonamiento-, y las estructuras subcorticales encargada de las emociones-), de esta forma se estará desarrollando la habilidad para autoregular las motivaciones, todo lo contrario de lo que les ocurre a los sujetos que padecen TDAH.

El déficit en la autorregulación de la motivación y el afecto, explicaría el hecho de que los niños con TDAH sean más emotivos comparados con otros niños, debido a que no inhiben sus primeras reacciones a la situación dada, por lo que no tienen tiempo de separar sus emociones de los hechos, desencadenándose problemas en sus relaciones con los demás -padres, profesores, compañeros, hermanos-, y haciéndolos parecer más inmaduros emocionalmente (Barkley, 2001, 2002, 2008; Ekman y Davidson, 1994; Frijda, 1994; Lang, 1995). Por otro lado, los chicos con TDAH tampoco son capaces de auto-regular sus motivaciones, o de automotivarse, para la consecución de un objetivo. Debido a lo cual, precisan de constantes refuerzos externos ${ }^{8}$ (halagos, puntos, gominolas, juguetes, dinero, etc.) para persistir en una tarea sin perder de vista el objetivo de la misma y sin distraerse.

\footnotetext{
${ }^{7}$ Que se genera cuando el cerebro es consciente del efecto que ha provocado una emoción.

${ }^{8}$ Resulta frecuente que los niños con TDAH presenten una fuerte tendencia a buscar recompensas inmediatas prefiriendo premios pequeños e inmediatos a grandes y aplazados- y se frustran en exceso cuando dichas recompensas no aparecen.
} 


\section{5.-Los Procesos de Análisis y Síntesis:}

Los procesos de análisis hacen referencia a la habilidad que muestra un sujeto para desglosar la información que recibe en partes o unidades más pequeñas; y los procesos de síntesis, a la habilidad que posee para recombinar esas partes en nuevos mensajes o instrucciones. Gracias a estos procesos se puede, por un lado, descomponer y analizar los mensajes y la información que es recibida, y por otro, combinar esas partes en un número casi infinito de formas y escoger el mensaje, o la conducta, resultante que sea más adecuada en ese momento.

Las personas con TDAH tienen dificultades en los procesos de análisis y síntesis, es decir, no los utilizan tan bien como otros niños que no presentan el trastorno (Barkley, 1997a, 2002, 2006a, 2006b, 2008). Concretamente, no son tan eficaces como los otros en exponer todas las soluciones que se les ocurran de una tarea, durante un tiempo determinado. Mientras juegan, no exploran o evalúan los juguetes tan bien como lo hacen los demás niños de su misma edad, y por último, cuando analizan las cosas que hacen, no las descomponen en tantas dimensiones como deberían, obviando -por ejemplo- partes esenciales para solucionar eficazmente un problema.

\section{Funciones Ejecutivas.}

De la neuropsicología del Sistema Ejecutivo, se derivan funciones denominadas, ejecutivas, por el control consciente, voluntario y finalista que ejercen sobre el comportamiento humano. En los últimos tiempos los conceptos de Sistema Ejecutivo y Funciones Ejecutivas (FEs, en lo sucesivo) han alcanzado un gran apogeo. Existen cada día más trabajos de investigación, libros y artículos en revistas prestigiosas, que están interesados en estudiarlos. Todo ello debido al imprescindible papel que juegan en el comportamiento humano.

A mediados de la década de los 70, Alexander Romanovich Luria, fue el predecesor de este concepto, aunque sin utilizarlo directamente hizo referencia a él en su libro "El Cerebro en Acción" (Luria, 1979). Pero, fue Lezak $(1982,1995)$ quien lo popularizó definiéndolo como capacidades cognitivas esenciales para llevar a cabo una conducta eficaz, creativa y aceptada socialmente. Estas funciones se pueden agrupar en torno a una serie de componentes, 
como son, las capacidades implicadas en la formulación de metas, las facultades empleadas en la planificación de los procesos y las estrategias para lograr los objetivos, y las aptitudes para llevar a cabo esas actividades de una forma eficaz.

No obstante, aún hoy día, no existe un claro consenso en la literatura científica en cuanto a la definición de FEs. Tirapú y colaboradores, (2008), han llevado a cabo una revisión de modelos que tratan de precisar y explicar este complejo constructo, llegando a la conclusión de que las FEs son una combinación de múltiples capacidades cognitivas que permiten la anticipación y el establecimiento de metas, la formación de planes, el inicio de las actividades, su autorregulación y la habilidad para llevarlas a cabo eficientemente. Las propuestas realizadas por los diferentes autores de los Modelos estudiados se complementan, coincidiendo todos en la idea de que las FEs posibilitan al sujeto controlar y regular su conducta a través de diversos procesos cognitivos, y que las regiones de la corteza prefrontal -caracterizada por su gran flexibilidad neuronal- y sus conexiones con distintas regiones subcorticales y con otras áreas cerebrales posteriores, son las encargadas del funcionamiento ejecutivo.

Dado que con frecuencia Sistema Ejecutivo y FEs se suelen utilizar como conceptos sinónimos, parece adecuado tratar de distinguirlos: los componentes psicológicos del Sistema Ejecutivo en relación con el TDAH, tal y como se ha reiterado en las páginas anteriores, hacen referencia: al control ejecutivo del comportamiento; la MT y su relación con el SAA; el lenguaje y su interiorización; la autorregulación de la motivación y el afecto; y los procesos de análisis y síntesis. Sin embargo, las FEs se refieren a: la planificación; la programación; la flexibilidad; la auto-monitorización; la persistencia; y la evaluación (véase tabla 1). Para poner en marcha estas FEs, se debe hacer uso de los componentes psicológicos del Sistema Ejecutivo -que también pueden ser empleados para la realización de otras tareas en las que no se precise el uso de las FEs-.

Pero, en qué consiste cada una de las FEs mencionadas:

i) Planificación: en función de los objetivos que demande la tarea o la situación. La planificación implicará la capacidad de: anticiparnos a los futuros acontecimientos, marcarnos los objetivos necesarios para la ejecución correcta de la tarea y desarrollar a tiempo estos objetivos siguiendo los pasos necesarios para la realización de los mismos.

ii) Programación de las acciones necesarias (específicas) para alcanzar la meta. 
iii) Control (auto-monitorización) de la puesta en marcha del plan y de su ejecución, con el fin de comprobar si se ajusta al plan elaborado y si se siguen todos los pasos necesarios para alcanzarlo.

iv) $\quad$ Flexibilidad para corregir los errores que vayamos apreciando, incorporar conductas nuevas en función de los cambios que se precisen y adaptarse al nuevo plan.

v) Persistencia, es decir, rechazo de otros estímulos, -de ideas de abandonar la actividad, etc.- que son irrelevantes para la ejecución del plan.

vi) Evaluación que implica, además de refuerzos positivos y/o negativos, reconocer el cumplimiento parcial/total del plan y finalizar la acción.

Tabla 1. Descripción de los componentes psicológicos del Sistema Ejecutivo y de las FEs

\begin{tabular}{ll}
\hline Componentes Psicológicos del SE & Funciones Ejecutivas \\
\hline Control Ejecutivo del Comportamiento & Planificación \\
MT y su relación con el SAA & Programación \\
Lenguaje y su interiorización & Automonitorización \\
Autorregulación motivación y afecto & Flexibilidad \\
Análisis y Síntesis & Persistencia \\
& Evaluación \\
\hline
\end{tabular}

a. SE: Sistema Ejecutivo.

b. MT: Memoria de Trabajo.

c. SAA: Sistema de Atención Anterior.

Todas las FEs comentadas están relacionadas y ordenadas jerárquicamente en función de la importancia que tienen para la ejecución correcta de una tarea. Es decir, para evaluar la ejecución de un plan, antes se ha de elaborar el plan, organizar los medios que son necesarios para llevarlo a cabo, controlarlo mientras se ejecuta, corregir y/o modificar el plan si es necesario durante el proceso de ejecución, persistir en la tarea siguiendo todos los pasos del plan hasta que finaliza, $\mathrm{y}$, finalmente, evaluarlo para ver si el resultado obtenido es coherente con la demanda inicial del plan. Un fallo en alguna de las FEs afectará de forma negativa al resultado final de la tarea.

Las personas con TDAH presentan dificultades en todas y cada una de las FEs mencionadas (Aman et al., 1998; Seidman et al., 2000, entre otros), lo que dificulta sobremanera sus quehaceres cotidianos. Concretamente, los niños con TDAH, manifiestan en primer lugar, déficit en las FEs de planificación y de programación lo que los lleva, por ejemplo a: no utilizar para su trabajo una planificación que los guíe con el objeto de saber en cada momento lo 
que han de hacer y el tiempo que tienen para hacerlo; hacer trabajos de baja calidad; dejarlo todo para el último momento; no utilizar guías de pensamiento mediante las cuales pueda desglosarse la tarea en pasos sencillos, para facilitar su ejecución; etc. Y en segundo lugar, déficit en la auto-monitorización, en la flexibilidad, en la persistencia y en la evaluación, que ocasiona problemas para: ir supervisando las tareas mientras se están llevando a cabo y una vez estén finalizadas; detectar y/o corregir los posibles errores; adaptarse a un nuevo plan, si es que el anterior no ha podido ser llevado a la práctica con éxito; centrarse en los detalles relevantes de la tarea, obviando los que son irrelevantes; mantenerse haciendo la tarea hasta conseguir finalizarla; etc.

\section{Cuál es el la Causa que Origina el TDAH}

Aunque profundizar sobre la etiología del TDAH no ha sido el objetivo fundamental del presente artículo, consideramos necesario al menos -aunque sea brevemente- hacer mención a nuestra postura sobre qué es lo que lo origina, porque entendemos que ello clarifica la concepción del trastorno que se propone.

Al definir TDAH hemos aludido a un trastorno intrínseco a la persona que lo padece, debido, a un retraso en el desarrollo neuropsicológico. Ahora bien, ¿cuál es la naturaleza de dicho retraso?

Los avances realizados en estos últimos años en cuanto a la búsqueda de la causa que origina este complejo trastorno, consideran que su origen es poligénico y multifactorial. De tal forma que implicaría una alteración en los genes (Barkley, 2006a, 2008; Faraone et al., 2005; Gizer, Ficks y Waldman, 2009) encargados de la recepción y/o transporte de neurotransmisores -como la dopamina y noradrenalina- muy presentes en los circuitos que inervan las zonas frontales del cerebro y las áreas subcorticales que se encuentran interconectadas con ellas y que a su vez serían las responsables de los procesos psicológicos del Sistema Ejecutivo y de sus funciones. Concretamente, los genes estudiados con más frecuencia se incluyen en el sistema catecalominérgico, concretamente los que más se asocian al TDAH son el gen receptor 4 de dopamina (DRD4) y el gen transportador de dopamina (DAT), (Faraone et al., 2005). Además, hay otros genes asociados como: el receptor 5 de dopamina (DRD5), el receptor 2 de dopamina (DRD2), la dopamina B-hidroxilasa (DBH), la tirosina hidroxilasa (TH), la catecolO-metiltransferasa (COMT) y la monoamino oxidasa A. En el sistema noradrenérgico, los 
receptores ADRA2A, ADRA2C y ADRA1C, y el transportador de norepinefrina; en el sistema serotoninérgico, los receptores de serotonina HTR1B y HTR2A, el transportador de serotonina y la triptófano hidroxilasa (Acosta, 2007). También se han descrito algunos loci del genoma (4q, 5q, 11q y 17q) que conllevan una mayor susceptibilidad para el desarrollo del TDAH (Gizer et al., 2009).

Ahora bien, a pesar de que la etiología del problema sea intrínseca al sujeto, no pueden desestimarse los factores extrínsecos como el ambiente familiar y escolar, ya que aunque no provocan el trastorno sí que pueden ser muy influyentes en él, agudizándolo o paliando la sintomatología derivada del mismo y sus efectos colaterales.

\section{Conclusiones}

Contar con una definición con la cual se pueda operar, para que los elementos integrantes de la misma puedan ser medibles, tratables y verificables, nos resulta fundamental. Por ello, partiendo del Modelo Híbrido de Autorregulación y de las Funciones Ejecutivas de Barkley (1997a) y de la relación que guarda el TDAH con las Dificultades en el Aprendizaje, hemos elaborado una definición operativa, abordada desde una perspectiva psicoeducativa, según la cual consideramos que se trata de un trastorno debido a un retraso en el desarrollo neuropsicológico que provoca disfunciones en los mecanismos de control ejecutivo e inhibición del comportamiento, que afecta de modo directo a los procesos psicológicos del Sistema Ejecutivo - tales como la MT y su relación con el SAA, la autorregulación de la motivación y el afecto, la internalización del lenguaje y los procesos de análisis y síntesis- y a sus FEs como planificación/organización, flexibilidad, automonitorización/evaluación- implicadas directamente en las tareas de enseñanza y aprendizaje y en la adaptación escolar, familiar y social.

El Sistema Ejecutivo y las FEs han resultado ser conceptos complejos de comprender y explicar, encontrado diferencias entre los expertos que pretenden definirlos. En lo que no existen discrepancias es en la consideración de que se encuentran implicados en el TDAH.

En un intento por facilitar la comprensión de lo que constituye el Sistema Ejecutivo y sus FEs y su relación con el trastorno, hemos planteamos un Modelo en el que el Sistema Ejecutivo está integrado por una serie de componentes estructurales y neuropsicológicos impli- 
cados en la manifestación del mismo. Los primeros hacen referencia a aquellos componentes del SNC como los lóbulos frontales y su relación con el cerebelo y otras estructuras subcorticales, como los ganglios basales, el sistema límbico y la amígdala, y a los circuitos neuronales que inervan las conexiones entre ellos (Barkley, 1997a, 2006a, 2008; Bradley y Golden, 2001; Brown, 2003; Frazer et al., 1999; Fuster, 1997; Goldberg, 2004, entre otros). Y los segundos, a procesos psicológicos tales como el control ejecutivo del comportamiento, la MT y su relación con el SAA, el lenguaje y su internalización, la autorregulación de la motivación y el afecto y los procesos de análisis y síntesis. Estos componentes tienen unas funciones a las que denominamos ejecutivas por el control consciente, voluntario y finalista que ejercen sobre el comportamiento. Las FEs hacen referencia a la planificación/organización, automonitorización/ evaluación y flexibilidad.

De este modo, consideramos que el TDAH es un reflejo de un retraso en la maduración de los componentes estructurales del Sistema Ejecutivo que provoca disfunciones en sus componentes neuropsicológicos, y por tanto en sus funciones.

La definición operativa de TDAH ofrecida nos resulta útil para el TDAH subtipo combinado según la clasificación del DSM-IV-TR. No obstante, para la próxima edición del DSM se esperan cambios importantes que afectarán a la vigente clasificación (Barkley, 2009). De hecho, de los tres subtipos tradicionales esperamos que se mantenga el TDAH subtipo combinado, por ser en realidad el único que existe. El subtipo con predominio de hiperactividad e impulsividad viene a ser una forma temprana de aparición del subtipo combinado. En cuanto al subtipo con predominio de déficit de atención, hay que hacer una apreciación, pueden ser; por un lado, niños que han crecido, y evolutivamente el exceso de actividad motora ha descendido e inicialmente presentaban el subtipo combinado; por otro, niños que presentan prácticamente todos los síntomas del subtipo combinado excepto uno o dos; y por último, niños que no son TDAH y presentan otro trastorno. Realmente se trata de un trastorno opuesto al TDAH, ya que las personas que lo manifiestan en vez de caracterizarse por ser hiperactivos se muestran "hipoactivas" -son lentas para todo, despistadas, excesivamente inatentas, introvertidas,...-. Barkley plantea sacar a este tipo de sujetos de la clasificación de TDAH, y poder denominarlos individuos de “Tempo Cognitivamente Lento".

Finalmente, esperamos que se abran nuevas vías de investigación interesantes que permitan establecer diferenciaciones importantes sobre la conceptualización, naturaleza, im- 
plicaciones y respuesta que las personas de "Tempo Cognitivamente Lentos" manifiesten a distintas formas de tratamiento y poder compararlas con el TDAH.

\section{Referencias}

Acosta, M.T. (2007). Aspectos genéticos y moleculares en el trastorno por déficit de atención/hiperactividad: búsqueda de los genes implicados en el diagnóstico clínico. Revista de neurología, 44(Supl 2), 37-41.

Aman, C., Roberts, R y Pennington, B. (1998). A neuropsychological examination of the underlying deficit in ADHD: the frontal vs. right parietal lobe theories. Developmental Psychology, 34, 956-969.

American Psychiatric Association. (1994). Diagnostic and statistical manual of mental disorders ( $4^{\mathrm{a}}$ ed.). Washington, DC: A.P.A.

American Psychiatric Association. (2002). Diagnostic and statistical manual of mental disorders ( $4^{\mathrm{a}}$ ed., rev). Washington, DC: A.P.A.

Baddeley, A.D. (1986). Working Memory. Londres: Oxford University Press.

Baddeley, A.D. (1990). Human memory: Theory and practice. Oxford: Oxford University Press.

Baddeley, A.D. (1992). Is working memory working? The fifteenth Barlett Lecture. The Quarteley Journal of Experiemental Psychology, 44 A, 1-31.

Baddeley, A.D. (1996). Exploring the central executive. Quarteley Journal of Experimental Psychology, 49 A, 5-28.

Baddeley, A.D. (2000). The episodic buffer: a new component of working memory. Trends in Cognitive Sciences 4, 417-423.

Baddeley, A.D. y Hitch, G.A. (1994). Developments in the concepts of working memory. Neuropsychology, 8, 484-493.

Baker, L. y Cantwell, D. (1992). Attention deficit disorder and speech/language disorders. Comprehensive Mental Health Care, 2, 3-16.

Barkley, R. A. (1997a). ADHD and the nature of self-control. New York, NY: Guilford Press.

Barkley, R. A. (1997b). Behavioral inhibition, sustained attention, and executive functions: Constructing a unifying theory of ADHD. Psychological Bulletin, 121, 65-94.

Barkley, R.A. (2001). The executive functions and self-regulation: an evolutionary neuropsychological perspective. Neuropsychology Review, 11 (1), 1-29. 
Barkley, R. A. (2002). Niños hiperactivos. Cómo comprender y atender sus necesidades especiales. Barcelona: Paidós.

Barkley, R. A. (2006a). Attention-deficit hyperactivity disorder. A handbook for diagnosis and treatment. New York, NY: Guilford Press.

Barkley, R. A. (2006b, febrero). Attention deficit hyperactivity disorder: Advances in nature, diagnosis and treatment. Conferencia presentada en el II Simposio para profesionales sobre actualizaciones en el TDAH, Barcelona, España.

Barkley, R. A. (2008, Enero). ADHD as a disorder of executive functioning: Implications for classroom management. Conferencia presentada en el II Congreso Nacional de TDAH 2008, Madrid, España.

Barkley, R.A. (2009). Avances en el diagnóstico y la subclasificación del trastorno por déficit de atención/hiperactividad: qué puede pasar en el futuro respecto al DSM-V. Revista de Neurología, 48 (Supl 2), S95-S99.

Berquin, P.C., Giedd, J.N., Jacobsen, L.K., Hambürger, S.D., Krain, B.A., Rapoport, J.L., et al. (1998). Cerebellum in attention: deficit hyperactivity disorder; a worphometric MRI study. Neurology, 50, 1087-1093.

Bradley, J.D. y Golden, C.J. (2001). Biological contributions to the presentation and understanding of attention deficit hyperactivity disorder: a review. Clinical Psychological Review, 21, 907-929.

Brown, T.E. (2001). The Brown Attention Deficit Disorder Scales. San Antonio, TX: Psychological Corporation.

Brown, T. E. (2003). Trastornos por déficit de atención y comorbilidades en niños, adolescentes y adultos. Barcelona: Masson.

Bush, G., Frazier, J.A., Rauch, S.L., Seidman, L.J., Whalen, P.J., Jenike, M.A., Rosen, B.R. y Biederman, J. (1999). Anterior cingulate cortex dysfunction in attentiondeficit/hyperactivity disorder revealed by fMRI and the Counting Stroop. Biological Psychiatry, 45, 1542-52.

Bush, G. (2008). Neuroimaging of attention déficit hyperactivity disorder: can new imaging finding be integrate in clinical practice? Child Adolesc Psychicatric Clin N Am, 17, $385-404$.

Capilla-González, A., Pazo, P., Campo, P., Maestrú, F., Fernández, A., Fernández-González, S. y Ortiz, T. (2005). Nuevas aportaciones a la neurobiología del trastorno por déficit de atención con hiperactividad desde la magnetoencefalografía. Revista de neurología, 40 (Supl 1), 43-47. 
Casey, J., Castellanos F.X., Giedd, J.N., Marsh, W.L., Hamburger, S.D., Schubert, A.B., Vauss, Y.C., Vaituzis, A.C., Dickstein, D.P., Sarfatti, S.E. y Rapoport, J.L. (1997). Implication of right frontostriatal circuitry in response inhibition and attention-deficit/hypertactivity disorder. Journal of the American Academy of Child and Adolescent Psychiatry, 36, 374383.

Castellanos, F.X., Giedd, J.N., Marsh, W.L. y Hamburger, S.D. (1996). Quantitative brain magnetic resonante Imaging in attention-deficit/hypertactivity disorder. Archives of General Psychiatry, 53, 607-616.

Castellanos, F.X, Lee, P.P, Sharp, W., Jeffries, N.O., Greenstein, D.K., Clasen, L.S., et al. (2002). Developmental trajectories of brain volume abnormalities in children and adolescents with attention-deficit/hyperactivity disorder. Journal of the American Medical Association, 288, 1740-1748.

Castellanos, F.X. y Tannock, R. (2002). Neuroscience of attention-deficit/hyperactivity disorder: the search for endophenotypes. Nature Reviews Neuroscience, 3(8), 617-28.

Castellanos, F.X. y Acosta, M.T. (2004). Neuroanatomía del trastorno por déficit de atención con hiperactividad. Revista de Neurología, 38 (Supl 1), 131-136.

Clements, S. y Peters, J. (1962): Minimal brain dysfunction in the school-age child, Archives of General Psychiatry, 6, 185-197. (Citado en Romero, 2002).

Cummings, J.L. (1993). Frontal-subcortical cicuits and human behaviour. Archives of Neurology, $50,873-880$.

Denckla, M. B. (1996a). A theory and model of executive function: A neuropsychologicalperspective. En G.R. Lyon y N.A. Krasnegor (Eds.), Attention, memory and executive function. Baltimere: Brookes.

Denckla, M. B. (1996b). Research on executive function in a neuropmental context: Application of clinical measures. Developmental Neuropsychology, 12, 5-15.

Díaz-Heijtz, R., Mulas, F. y Forssberg, H. (2006). Alteraciones de los patrones de los marcadores de la dopamina en el trastorno por déficit de atención e hiperactividad. Revista de Neurología, 42 (Supl 2), 19-23.

Ekman, P. y Davidson, R. (1994). The nature of emotion: fundamental questions. NY: Oxford University Press.

Ernest, M., Zametkin, A.J., Philips, R.L. y Cohen, R.M. (1997). Cerebral glucose metabolism in adolescent girls with attention deficit hyperactivity disorder. Journal of American Academy Child Adolescent Psychiatry 36, 1399-1406. 
Faraone, S.V. y Biederman, J. (1998). Neurobiology of attention-deficit hyperactivity disorder. Biological Psychiatry, 44, 951-958.

Faraone, S.V. (2004). Genetics of adult attention-deficit/hyperactivity disorder. Psychiatry Clinics of North America, 27, 303-321.

Faraone, S.V., Perlis, R.H., Doyle, A.E., Smoller, J.W., Goralnick, J.J., Holmgren, M.A. y Sklar, P. (2005). Molecular genetics of attention-deficit/hyperactivity disorder. Biological Psychiatry 57(11), 1313-23.

Félix, V. (2005). Perspectivas recientes en la Evaluación Neuropsicológica y Comportamental del TDAH. Electronic Journal of Research in Educational Psychology, 3, 215-232.

Félix, V. (2006). Recursos para el diagnóstico psicopedagógico del TDAH y comorbilidades. Electronic Journal of Research in Educational Psychology, 4(10), 623-642.

Filipek, P.A., Semrud-Clikeman, M., Steingard, R.J., renshaw, P.F., Kennedy, D.N. y Biederman, J. (1997). Volumetri MRI analysis comparing subjects having attentiondeficit hyperactivity disorder and normal controls. Neurology, 48, 589-601.

Fuster, J.M. (1997). The prefrontal cortex. New York, NY: Raven.

Frazer, A., Gerhardt, G.A. y Daws, L.C. (1999). New views of biogenic amine transporter function: Implications for neuropsychopharmacology. International Journal of Neuropsychopharmacology, 2, 305-20.

Frijda, N.H. (1994). Emotions are functional, most of the time. En P. Ekman y R.J. Davidson (Eds.), The nature of emotion: fundamental questions (pp. 112-122). NY: Oxford University Press.

Gizer, I.R., Ficks, C. y Waldman, I.D. (2009). Candidate gene studies os ADHD: a meta-analytic review. Human Genetic, 126, 51-90.

Goldberg E. (2004). El cerebro ejecutivo ( $2^{a}$ ed). Barcelona: Crítica.

Goldstein, K. (1942). After-effects of brain injuries in War. New York, NY: Grune \& Stratton.

Gustafsson, P., Thernlund, G., Ryding, E., Rosén, I. y Cederblad, M. (2000). Associations between cerebral blood-flow measured by single photon emission computed tomography (SPECT), electro-encephalogram (EEG), behaviour symptoms, cognition and neurological soft signs in children with attention-deficit hyperactivity disorder (ADHD). Acta Pediátrica, 89, 830-835.

Hernández-Muela, S., Mulas, F. y Mattos, L. (2005). Contribución del cerebelo a los procesos cognitivos. Revista de Neurología, 40 (Supl 1), 57-64.

Herschkowitz, N. (1988). Brain development in the fetus, neonate and infant. Biology of the Neonate, 54, 1-9. 
Hinshaw, S.P., Hender, B. y Whalen, C.K. (1984). Cognitive-behavioral and pharmacologic interventions for hyperactive boys: Comparative and combined effects. Journal of Consulting and Clinical Psychology, 52, 739-749.

Hoffman, H. (1865). Die Geschichte vom Zappel-Philipp. En H. Hoffman (Ed.), Der Struwwelpeter. Germany: Pestalozzi-Verlag. (Citado en Barkley, 2006).

Hohman, L.B. (1922). Postencephalitic behavior disorders in children. Johns Hopkins Hospital Bulletin, 380, 372-376.

Lang, P.J. (1995). The emotion probe: Studies of motivation and attention. American Psychologist, 50, 372-385.

Lawrence, V., Houghton, S., Tannock, R., Douglas, G., Durkin, J. y Whiting, K. (2002). ADHD outside the laboratory: boys' executive function performance on tasks in videogame play and on a visit to the zoo. Journal of Abnormal Child Psychology, $30(5), 447-462$.

Lezak, M.D. (1982). The problem of assessing executive functions. International Journal of Psychology, 17, 281-29

Lezak, M.D. (1995). Neuropsychological assessment. Oxford, UK: Oxford University Press.

Luria, A.R. (1979). Atención y memoria. Barcelona: Fontanella.

Luria, A.R. (1984). El cerebro en acción. Barcelona: Martínez Roca.

Martín, D., Fernández, A., García, J.M. y Quiñones, D. (2010). Neuroimagen en el trastorno por déficit de atención/hiperactividad. Revista de Neurología,50(Supl 3), 125-133.

McCarthy, R.A., y Warrington, E.K. (1990). Cognitive neuropsychology. A clinical introduction. San Diego: Academic Press.

Miranda, A., Roselló, B., y Soriano, M. (1998). Estudiantes con deficiencias atencionales. Valencia: Promolibro.

Miranda, A., Presentación, M.J. y Soriano, M. (2002). Effectiveness of a school-based multicomponent program for the treatment of children with ADHD. Journal of Learning Disabilities, 35(6), 546-562.

Miranda, A., Félix, V. y Ávila, C. (2005). Validez de las tareas neuropsicológicas en la evaluación del TDAH. Psicología General y Aplicada, 58(3), 297-307.

Mulas, F., y Morant, A. (2006). Abordaje farmacológico de los trastornos por déficit de atención con hiperactividad. Descargado el 12 de noviembre de 2007 de http://www.uninet.edu/union99/congress/confs/npd/06Mulas.html 
Mulas, F., Mattos, L., de la Osa-Langreo, A., y Gandía, R. (2007). Trastorno por déficit de atención/hiperactividad: a favor del origen orgánico. Revista de Neurología, 44 (Supl 3), 47-49.

Norman, D.A. y Shallice, T.A. (1980). Attention to action: willed and automatic control of behaviour. Center for human information processing. Technical report. San Diego: University of California, p. 99. (Citado en Norman y Shallice, 1986).

Norman, D.A. y Shallice, T.A. (1986). Attention to action: willed and automatic control of behaviour. En R.J. Davidson, G.E. Schwartz y D. Shapiro (Eds.). Consciousness and self-regulation. Vol. IV. (pp. 1-18). NY: Phenum Press.

Organización Mundial de la Salud (1995). Clasificación Internacional de Enfermedades (10 ed.). Madrid: Meditor.

Pennington, B.F. (1991). Diagnosing Learning Disorders: A Neuropsychological Framework. NY: Guilford Press.

Pennington, B.F., y Ozonoff, S. (1996). Executive functions and developmental psychopatology. Journal of Child Psychology and Psychiatry, 37, 51-87.

Pine, D., Grun, J. y Peterson, B. (2001). Mapping brain circuits in developmental psychopatology: ADHD and anxiety as examples. En D. Dougherty, y S. Rauch, (Eds.). Brain imaging (pp. 335-366). American Psychiatric Association Press, Washington, DC.

Romero, J.F. (2002). Memoria de oposición a Cátedra. Departamento de Psicología Evolutiva y de la Educación: Universidad de Málaga.

Romero, J.F. y Lavigne, R. (2005). Dificultades en el Aprendizaje: Unificación de Criterios Diagnósticos. I. Definición, Características y Tipos. Sevilla: Junta de Andalucía.

Romero, J.F. y Lavigne, R. (2006). Dificultades en el Aprendizaje: Unificación de Criterios Diagnósticos. II. Procedimientos de Evaluación y diagnóstico. Sevilla: Junta de Andalucía.

Root, R.W. y Resnick, R.J. (2003). An update on the diagnosis and treatment of attentiondeficit/hyperactivity disorder in children. Professional Psychology: Research and Practice, 34, 34-41.

Rubia, K., Overmeyer, S. y Taylor, E. (1999). Hypofrontality in attention deficit hyperactivity disorder during higher cortical order motor control: a study using fMRI. American Journal of Psychiatry, 156, 891-896.

Sánchez, R. y Narbona, J. (2001). Revisión conceptual del sistema ejecutivo y su estudio en el niño con trastorno por déficit de atención e hiperactividad. Revista de Neurología, 33 (1), 47-53. 
Still, G.F. (1902). Some abnormal psychical conditions in children. Lancet, 1, 1008- 1012, 1077-1082, 1163-1168. (Citado en Barkley, 2006a y Taylor, 1990).

Strauss, A.A. y Werner, H. (1942). Disorder of conceptual thinking in the brain-injured child. Journal of Nervous and Mental Disease, 96, 153-172.

Strauss, A.A. y Lehtinen, L.E. (1947). Psychopathology and education of the brain-injured child. New York, NY: Grune \& Stratton.

Swanson, H.L. (1996). Swanson Cognitive Processing Test (S-CPT). A dynamic Assessment Measure. Austin, Texas: Pro-ed.

Swanson, H.L. (2000). Are Working Memory Deficits in Readers with Learning Disabilities Hard to Change?. Journal of Learning Disabilities, 33(6), 551-556.

Tannock, R. y Schachar, R. (1996). Executive dysfunction as an underlying mechanism of behaviour and language problems in attention deficit hyperactivity disorder. En J.H. Beichman, N.J. Cohen, M.M. Konstatereas y R. Tannock (Eds.), Language, learning, and behavioural disorders. Developmental, biological, and clinical perspectives, (pp. 128-155). NY: Cambridge University Press.

Taylor, E.A. (1990). El niño hiperactivo. Barcelona: Martínez Roca.

Teicher, M.H., Anderson, C.M. y Polcari, A. (2000). Functional deficits in children with attention deficit hyperactivity disorder shown with functional magnetic resonance imaging relaxometry. Nature Medicine, 6, 470-474.

Tirapú, J., García, A., Luna, P., Roig, T. y Pelegrín, C. (2008a). Modelos de funciones y control ejecutivo (I). Revista de Neurología, 46(11), 684-692.

Tirapú, J., García, A., Luna, P., Roig, T. y Pelegrín, C. (2008b). Modelos de funciones y control ejecutivo (II). Revista de Neurología, 46(12), 742-750.

Vygotsky, L.S. (1987). Pensamiento y Lenguaje: teoría del desarrollo cultural de las funciones psíquicas. Buenos Aires: La Pléyades.

Wheeler, M.A., Stuss, D.T. y Tulving, E. (1997). Toward a theory of episodic memory: the frontal lobes and autonoetic consciousness. Psychological Bulletin, 121, 331-354.

Willcutt, E.G., Doyle, A.E., Nigg, J.T., Faraone, S.V., y Pennington, B.F. (2005). Validity of the executive function theory of attention deficit/hyperactivity disorder: a metaanalytic review. Biology of Psychiatry, 57(11), 1336-1346.

Wilson, K.M. y Swanson, H.L. (2001). Are Mathematics Disabilites Due to a Domain-General or Domain-Specific Working Memory Deficit? Journal of Learning Disabilities, 34(3), 237-248. 
Ygual, A. (2003). Problemas de Lenguaje en Estudiantes con Déficit Atencional. Tesis Doctoral, Departamento de Psicología evolutiva y de la Educación, Universitat de Valencia.

Zametkin, A.J., Nordahl, T.E., Gross, M., King, A.C., Semple, W.E., Rumsey, J., Hamburger, S. y Cohen, R.M. (1990). Cerebral glucose metabolism in adults with hyperactivity of childhood onset. New England Journal of Medicine, 323, 1361-1366.

Zametkin, A.J., Liebenauer, L.L., Fitzgerald, G.A., King, A.C., Minkunas, D.V., Herscovitch, P., Yamada, E.M. y Cohen, R. M. (1993). Brain metabolism in teenagers with attention-deficit hyperactivity disorder. Archives of General Psychiatry, 50, 333-340. 